\title{
Temporal Interactions in the Cat Visual System. I. Orientation- Selective Suppression in the Visual Cortex
}

\author{
Sacha B. Nelson \\ Robert Bosch Vision Research Center, The Salk Institute for Biological Studies, San Diego, California 92138, and \\ Department of Biology, University of California at San Diego, La Jolla, California 92093
}

\begin{abstract}
The perception of a visual contour depends on the spatial and temporal context in which it is viewed. Interactions between visual contours are believed to underlie a wide range of perceptual phenomena, including geometric illusions and aftereffects, contrast adaptation, and visual masking. The physiological mechanisms that might underlie such interactions were studied in the visual cortex of the cat by recording responses of single neurons to pairs of brief stationary stimuli that were separated in time. The results revealed a long-lasting, orientation-selective suppression, termed "paired-pulse suppression," which was strongest at the cell's preferred orientation, but which was more broadly tuned for orientation than the excitatory response of the cell. Although the strength and duration of the suppression varied widely, some degree of response reduction was present in most cells studied. The function of this suppression may be to regulate the gain with which visual inputs are transmitted to cortical neurons, thus preventing response saturation and positive feedback.
\end{abstract}

Orientation-selective inhibition is a well-documented feature of visual cortical physiology (Creutzfeldt et al., 1974; Sillito, 1977; Ferster, 1986). The organization and function of this inhibition have, however, been controversial. Two conflicting ideas about the orientation tuning of inhibition have been proposed. The first, known as the cross-orientation model (Morrone et al., 1982), proposes that inhibition exists mainly between neurons tuned to widely different orientations. This type of inhibition would enhance the orientation selectivity of single neurons by inhibiting their responses to all but a narrow range of orientations. The second, known as the lateral inhibition model (Blakemore et al., 1970; Nelson, 1985), proposes that inhibition is strongest between cells tuned to similar orientations and is weak or absent between cells preferring widely different orientations. Although this type of inhibition could not be the sole mechanism by which cortical neurons become orientation selective, it could sharpen their orientation tuning if it were broadly tuned relative to their excitatory inputs. A variant of the lateral inhibitory model, suggested by recent physiological results (Ferster, 1986,

\footnotetext{
Received July 5, 1989; revised Aug. 3, 1990; accepted Aug. 30, 1990.

I am grateful to Dr. Simon LeVay for support and advice, to Ralph Siegal, Tom Albright, Karen Dobkins, Gene Stoner, Avi Chaudhuri, and Gina Turrigiano for helpful discussions, and to Kent Allen for technical assistance. This work was supported by NIH Grant EY05551 to Simon LeVay and by Medical Scientist Training Grant PHSGM07198.

Correspondence should be addressed to Sacha Nelson, The Salk Institute for Biological Studies, P.O. Box 85800, San Diego, CA 92138.

Copyright (C) 1991 Society for Neuroscience 0270-6474/91/1 10344-13\$03.00/0
}

1987), argues that inhibition is not more broadly tuned than excitation, and hence that it must serve some other function besides sharpening orientation selectivity.

Originally, the lateral inhibitory model was suggested as an explanation for a number of orientation-dependent illusions. These include the misperception of briefly presented angles (Andrews, 1967; Bouma and Andriessen, 1970; Carpenter and Blakemore, 1973), the tilt illusion and aftereffect (Tolhurst and Thompson, 1975; O'Toole and Wenderoth, 1977), and geometric illusions such as those of Hering, Poggendorff, and Zöllner (Wallace, 1969). A common feature of these phenomena is that acute angles appear to be expanded. The explanation for the apparent expansion is based on the idea that 2 adjacent stimuli of similar orientation (like the 2 sides of an acute angle) will activate overlapping but nonidentical populations of cortical neurons, and that lateral inhibition will cause the 2 distributions to "repel" each other. Thus, local orientation differences will be accentuated by cortical lateral inhibition in much the same way that local luminance differences are accentuated by lateral inhibition in the retina. According to the lateral inhibition hypothesis, the degree of angle expansion should depend on the relative strength and degree of overlap of the underlying distributions of activity. This is in fact observed: Reducing the contrast of the inducing stimulus (Parker, 1974; Wallace, 1975), making the inducing and test stimuli nonadjacent (Wallace, 1969; Tolhurst and Thompson, 1975), or using stimuli of widely different spatial frequency (Georgeson, 1973; Ware and Mitchell, 1974) or orientation (Klein et al., 1974; Tolhurst and Thompson, 1975) reduces the magnitude of the illusions.

An important clue to the cellular mechanism underlying the proposed lateral inhibition is its time course. Several experiments have suggested a time course that is slower than that typically associated with synaptic inhibition. By varying the length of time stimuli were presented, Andrews (1967) concluded that the lateral inhibition had a time constant of 200500 msec. Similar estimates have been obtained by Carpenter and Blakemore (1973), O'Toole (1979), and Reynolds (1978). These experiments suggest that, when 2 oriented stimuli are presented simultaneously, their interaction takes some time to develop. However, 2 stimuli can also interact when they are presented consecutively. One stimulus can alter the apparent orientation of another stimulus (the tilt aftereffect) or its contrast (contrast adaptation, or pattern masking). Depending on the experimental design, these consecutive effects can last for less than a second, many seconds, minutes, or even longer. Initially, it was proposed that these consecutive effects arise because of fatigue following prolonged excitation (Sutherland, 1961). Sub- 
sequently, a number of authors have argued that the tilt illusion, tilt aftereffect, and contrast adaptation result from a common mechanism, namely, lateral inhibition (Dealy and Tolhurst, 1974; Tolhurst and Thompson, 1975; Magnussen and Kurtenbach, 1980; Greenlee and Magnussen, 1988). Evidence supporting this idea includes the observations that the tilt illusion and aftereffect are similar in magnitude (Tolhurst and Thompson, 1975) and have a similar dependence on contrast (Parker, 1972, 1974), spatial proximity (Wallace, 1969; Tolhurst and Thompson, 1975), and inspection time (Calvert and Harris, 1985; Harris and Calvert, 1989). The tilt illusion, tilt aftereffect, and contrast adaptation also have similar dependencies on orientation (Magnussen and Kurtenbach, 1980; Greenlee and Magnussen, 1988) and spatial frequency (Pantle and Sekuler, 1968; Blakemore and Campbell, 1969; Georgeson, 1973). Furthermore, the perceptual effects of the simultaneous and successive illusions are additive (Magnussen and Kurtenbach, 1980; Kurtenbach and Magnussen, 1981). The idea that aftereffects and adaptation arise from prolonged excitation has also been called into question by the finding that large aftereffects can be produced by very brief exposures (though the duration of these effects is also brief; Sekuler and Littlejohn, 1974; Wolfe, 1984) and by experiments in which adaptation was evoked by stimuli that, by psychophysical (Dealy and Tolhurst, 1974; Sharpe, 1974) or physiological (Maffei et al., 1973; Ohzawa et al., 1982) criteria, failed to cxcitc the cclls undergoing adaptation. Taken together, the psychophysical data are consistent with the existence of a suppressive cortical mechanism (assumed but not proved to be lateral inhibition) that can build up over time and can substantially outlast the stimuli that evoke it.

Physiological evidence consistent with the existence of lateral inhibition in the orientation domain has come from intracellular recordings (Creutzfeldt et al., 1974) and from extracellular studies in which inhibition was inferred from the ability of a surrounding stimulus to suppress the response to a central one (Blakemore and Tobin, 1972; Fries et al., 1977; Nelson and Frost, 1978). This surround effect differs from the lateral inhibition inferred from the psychophysical studies mentioned above in 2 important ways: First, it is relatively short lived (it outlasts the inhibitory stimulus by $100 \mathrm{msec}$ ). Second, the surround effect operates over many degrees of visual angle, while the distance over which contours can intcract to produce angle expansion is limited to a degree or less (Wallace, 1969; Tolhurst and Thompson, 1975; Wenderoth and Johnstone, 1988).

The aim of the present study was to ascertain whether or not cortical neurons show local, long-lasting orientation-selective suppression. The method used was to present cortical neurons with pairs of stimuli that are separated in time rather than in space. The results indicate that presentation of a brief condition stimulus can profoundly suppress the response to a subsequent test stimulus. The suppression can last many hundreds of msec and has an orientation selectivity that is substantially broader than that for excitation of the cell, as predicted for the scheme of lateral inhibition in the cortex.

\section{Materials and Methods}

Recordings. Extracellular recordings were obtained from the visual cortex of 17 paralyzed, anesthetized adult cals. Anesthesia was initiated with an intramuscular injection of a ketamine-xylazine mixture, followed by intravenous pentobarbital, and maintained with pentobarbital (1.4-2.0 $\mathrm{mg} / \mathrm{kg} / \mathrm{hr}$ ). Prior to initiating paralysis (and in pilot experiments in which paralytic agents were not used), the anesthetic dose was titrated to insure that animals were completely unresponsive to painful stimuli. Heart rate was monitored in paralyzed animals, and additional anesthetic was infused whenever it increased in response to noxious stimulation. Paralysis was maintained with gallamine triethiodide, and animals were artificially respirated (Harvard Apparatus respirator). The barbiturate and gallamine were infused continuously (Harvard Apparatus infusion pump) through a cannula in the femoral vein. Expired $\mathrm{CO}_{2}$ was monitored (Gould Goddard Capnograph) and maintained between 3.5 and $4.0 \%$ by adjusting respiratory rate and tidal volume. Rectal temperature was maintained at $37.5^{\circ}$ with the use of a heating pad. The pupils were dilated with atropine, and the nictitating membranes were retracted with phenylephrine. Plastic contact lenses of appropriate correction were used to protect the corneas from drying and to focus the eyes on a tangent screen $57 \mathrm{~cm}$ away. Back projection of retinal landmarks with a fiber optic probe was used to verify proper focus and to determine the location of the area centralis in each eye (Nikara et al., 1968). A small hole was drilled in the skull overlying the representation of the central part of the visual field, and the dura was carefully removed. In order to protect the brain and minimize pulsations, the exposed cortex was covered with a warm agar solution and warmed petroleum jelly.

Data were obtained from 21 penetrations into area 17 (14 animals) and from 6 penetrations into area 18 (3 animals). Lacquer-insulated tungsten microelectrodes (resistances of 1-8 M , exposed tip lengths of 5-15 $\mu \mathrm{m}$; Hubel, 1957) were advanced through the cortex using a hydraulic microdrive (Kopf). Signals were amplified (World Precision Instrument), fed through a window discriminator (Winston Electronics), displayed on an oscilloscope (Tektronics 5113), and played over an audio monitor. Recordings were obtained from all single units that could be held and reliably discriminated. At the end of each penetration, 2-5 lesions were made at different locations by passing $4 \mu \mathrm{A}$ positive constant current through the recording electrode for a period of $4 \mathrm{sec}$. At the end of the experiment, the animals were killed by a barbiturate overdose and perfused with formal saline. Sections from blocks of tissue containing the electrode tracts were made on a Vibratome or freezing microtome, then stained with cresyl violet to reveal laminar and area boundaries. Laminar positions of recorded units were determined from camera lucida drawings of relevant sections.

Stimuli. Upon isolating a unit, its receptive field was mapped using hand-projected light bars, edges, and spots. Quantitative tests were made using stimuli generated by a Picasso image synthesizer (Innisfree) controlled by a PDP-1 1/73 computer (Digital Electronics). The stimuli were displayed on a Hewlitt Packard monitor (1311B, P31 phosphor) and had a maximum luminance of $8.0 \mathrm{~cd} / \mathrm{m}^{2}$. The background luminance was $0.5 \mathrm{~cd} / \mathrm{m}^{2}$. Stimuli consisted of light or dark bars, either stationary or moving, presented monocularly to the eye that was dominant for that cell. The length of the stimuli were adjusted to be optimal for each cell. For most cells, the length was slightly longer than the length of the receptive field as mapped with hand-held stimuli. For end-stopped cells, the length was reduced until the response was maximal, either judged qualitatively or as determined by quantitative testing. The various stimuli used in each test were interleaved randomly.

Orientation and direction selectivity were assessed concurrently in a test in which moving bars of optimal size and velocity were presented at each of 12 directions ( 6 orientations, each presented moving forward and back). The directions chosen were equally spaced and included the direction preferred by the cell as estimated using hand-held stimuli or brief runs of computer-driven stimuli. In cases where it was apparent from the resulting tuning curve that the actual preferred direction lay between 2 of the chosen directions, the directions were shifted appropriately, so as to include the optimal direction, and the test was repeated. The described technique was chosen to optimize the number of cells that could be recorded during an experiment while maintaining adequate sampling to accurately measure the preferred orientation and degree of orientation selectivity. Although conclusions could not be drawn about the fine structure of orientation tuning curves derived in this way, the methods were judged to be adequate for characterizing cells with tuning curve half-widths greater than $15^{\circ}$ (which account for the great majority of cells encountered in previous studies), and for studying paired-pulse suppression, which is more broadly tuned (see Figs. 7, 8).

The spatial distribution of on and off responses were assessed in a line-weighting (static field) test in which stationary bars of preferred orientation were presented at successive locations along the cell's preferred axis of movement. Responses to stimulus onset and offset were measured separately. 

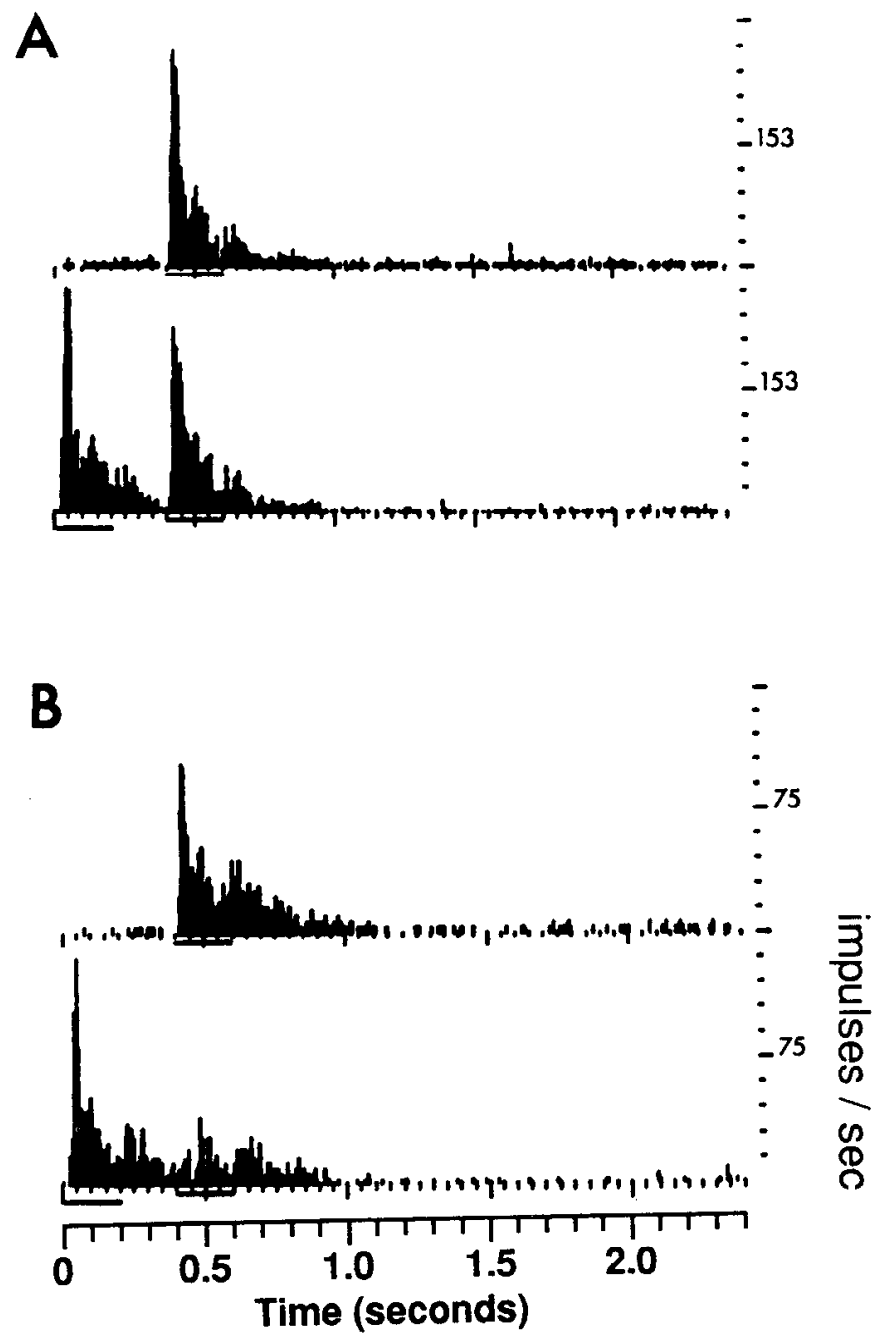

Figure 1. PSTHs from masking tests on 2 simple cells. On alternate trials, the test stimulus was presented alone (upper histogram in each panel) or was preceded by an identical condition stimulus (lower histogram in each panel). Stimuli were stationary bars of optimal size and orientation flashed for $200 \mathrm{msec}$ (as indicated by markers below each histogram) at the most responsive location within the receptive field. The ISI was also 200 msec. Each histogram contains the summed response to 20 repetitions. Bins are $10 \mathrm{msec}$ each. Numbers to the right of the vertical scale indicate $50 \%$ of the peak firing rate (in spikes/sec). Horizontal scale is time (small tick marks occur each $50 \mathrm{msec}$; largc tick marks occur each $500 \mathrm{msec}$ ). A, Responses of a cell that did not show suppression. $B$, Responses of a cell that did show suppression.

Temporal interactions were assessed in a standardized paired-pulse test in which pairs of brief stationary stimuli were presented. The stimuli were identical light or dark bars of optimal size and orientation presented at the most responsive region within the receptive field. The 2 stimuli were on for $200 \mathrm{msec}$ each and were separated by a 200 -msec interstimulus interval (ISI).

For most cells, additional paired-pulse tests were performed in which the ISI was varied or in which one feature (such as the orientation, contrast, or position) of the first (condition) stimulus was varied, while the second (test) stimulus remained unchanged. Some cells were also tested with stationary bars that flickered on and off at various temporal frequencies.

Analysis. The time of occurrence of cach spike was recorded (to the nearest $0.1 \mathrm{msec}$ ) and used to construct binned or smoothed poststimulus time histograms (PSTHs). Smoothing was performed by convolving the spike train with a Gaussian filter having a standard deviation of 10 or $20 \mathrm{msec}$. In order to calculate the magnitude of the response to each stimulus, all spikes were binned into a cumulative PSTH (10-msec bins) that contained the summed responses for all trials. The 10-bin period containing the greatest number of spikes was found, and the responses occurring during this period of each individual trial were then averaged to obtain a mean and a standard error of the mean. These values were then used to construct tuning curves. For calculation of the indices described below, spontaneous activity was first subtracted from each response. For each cell, the following indices were computed from responses to moving bars:

A directionality index (DI; $0=$ fully directional, $1=$ nondirectional):

$$
\mathrm{DI}=(\text { response to null)/(response to preferred). }
$$

An orientation index (OR; $0=$ fully oriented, $1=$ nonoriented):

$\mathrm{OR}=$ (response to orthogonal)/(response to preferred).

From the results of the paired-pulse test, a temporal interaction index was calculated (TI; $0=$ complete suppression, $1=$ no suppression, $>1$ - facilitation):

$$
\mathrm{TI}=(\text { test response }) /(\text { control response). }
$$

The control response is the response to the test stimulus when it is presented alone; the test response is the response to the test stimulus when it is preceded by a condition stimulus.

\section{Results}

Standardized paired-pulse tests (identical condition and test stimuli separated by a 200 -msec ISI) were performed on 133 neurons in area 17 and 29 neurons in area 18 . The results varied widely from one cell to the next. For some cells, there was no significant effect of the condition stimulus on the test response. An example of such a cell is shown in Figure 1A. The uppermost histogram shows the response to the test stimulus presented alone. The second histogram shows that the response remained relatively unchanged when the test stimulus was preceded by an identical condition stimulus. For other cells, such as that shown in Figure $1 B$, the response to the test stimulus was nearly entirely suppressed when it was preceded by an identical condition stimulus.

Most cells studied showed behavior that was intermediate between that shown by the 2 cells in Figure 1. Because changes in firing rate could be due in part to intrinsic response variability, the responses to the condition and test stimuli were compared statistically for each cell. Just over half of the cells studied in area $17(71 / 133 ; 53.4 \%)$ showed significant suppression (paired $t$ test; $p<0.5$ ). Even among the cells that did not show a significant change, however, somc degrce of response reduction (i.e., TI $<1.0$ ) was significantly more common than response enhancement (TI $>1.0 ; p=0.003,1$-sample sign test). For these cells, the mean TI was 0.86 , a value significantly different from $1.0(p<0.001,2$-tailed $t$ test). Suppression was equally common among simple and complex cells (as classified using hand-held stimuli). The degree of suppression varied continuously across the population studied; there was no indication of separate populations of suppressed and nonsuppressed cells. Facilitation was much less common: only 2 out of 133 cells $(1.5 \%)$ showed significant facilitation.

A smaller population of neurons in area 18 was also studied. Approximately $1 / 4$ of the cells $(7 / 29 ; 24.1 \%)$ showed significant suppression. Two cells showed significant facilitation (6.9\%), and the remainder had responses that showed no significant change ( 20 cells; $69 \%$ ).

\section{Correlation with other cellular properties}

Laminar position. Although cells showing suppression were found in all layers, they were much less frequent in layer 5 than in other cortical layers. This is illustrated in Figure 2 for the 122 


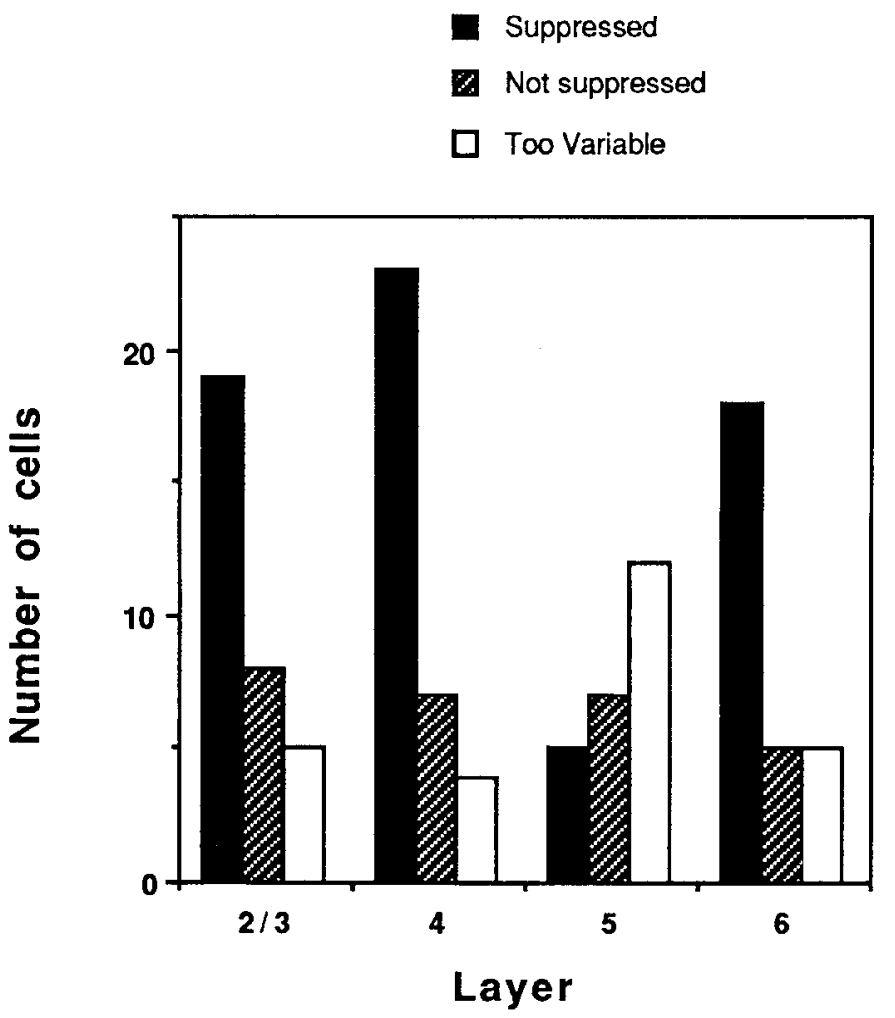

Figure 2. Laminar distribution of temporal interaction effects. Laminar positions of 122 area 17 cells were reconstructed, and each cell was assigned to 1 of 3 categories (see text for further details). Solid bars indicate cells that showed significant suppression $(p<0.5$; paired $t$ test). Hatched bars indicate cells in which suppression was insignificant or absent. This category also included 1 cell that showed significant facilitation. Open bars indicate cells that lacked significant suppression but that had highly variable responses. For these cells, the variability was such that even a 2:1 difference in the mean responses to condition and test stimuli would not be statistically significant. Note that layer 5 had far fewer cells showing significant suppression than did the other layers.

cells in area 17 whose laminar positions were known. (One penetration containing the remaining 11 cells was not reconstructed.) Cells in different layers may show different degrees of variability in their responses, and this may influence the degree to which they show statistically significant suppression. In order to facilitate comparison, cells were assigned to 1 of 3 classes: cells that showed significant suppression $(p<0.5$; paired $t$ test), cells that did not show suppression, and finally, cells for which responses were so variable that it was difficult to assess whether suppression was present or not. Cells were included in this latter category if the variability was such that even a $2: 1$ difference in the mean responses to condition and test stimuli would not be statistically significant.

Orientation and directional tuning. No correlation was found between the degree of orientation and directional tuning exhibited by a cell and the degree of suppression it exhibited. The relationship between the TI and the DI is shown in Figure $3 A$. No significant correlation is evident from the plot. Figure $3 B$ illustrates the relationship between the TI and the OR. Once again, there was no consistent difference between cells that showed a high degree of suppression and those that did not. Another measure of orientation selectivity, the tuning curve half-width, was also not correlated with the TI.

Balance and separation of on and off subfields. There was no
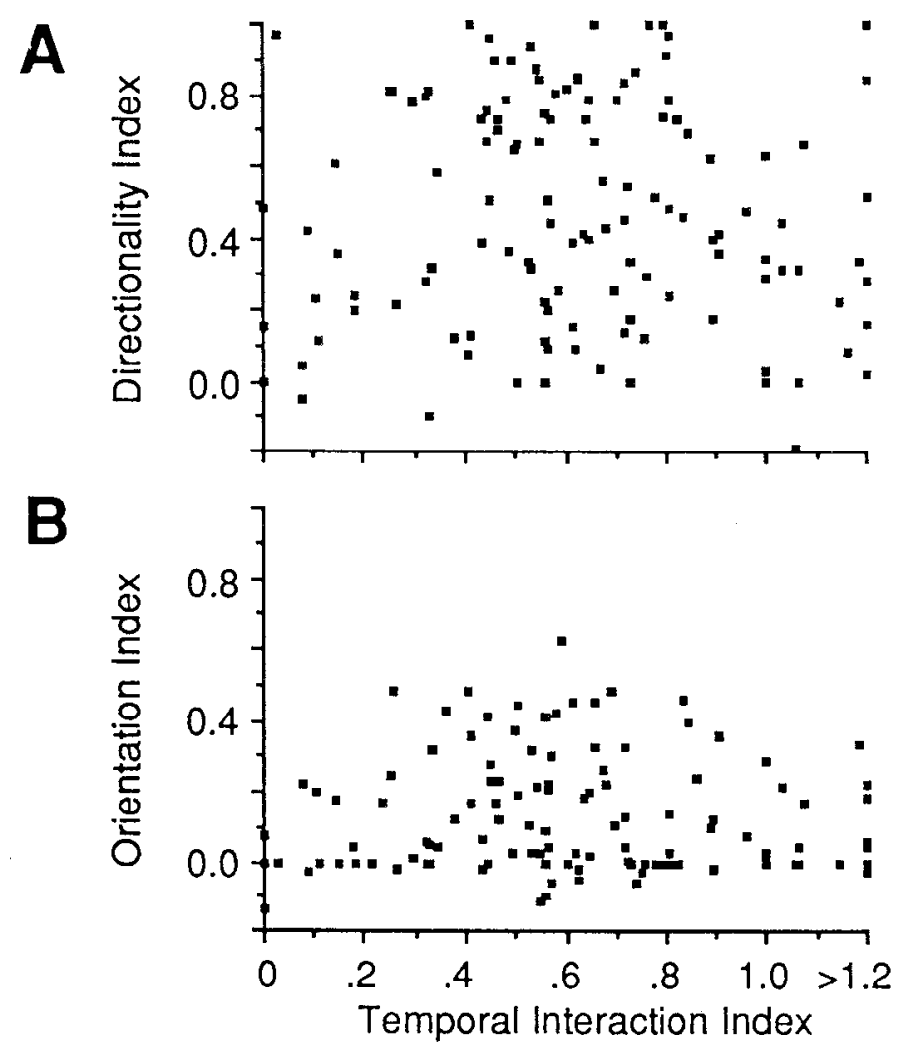

Figure 3. Relationship of temporal interactions to direction and orientation tuning. $A$ shows the relationship between the TI and the DI. Highly directional cells (DI close to 0 ) were no more likely than nondirectional cells to display strong suppression (TI close to 0 ). $B$ shows a similar lack of correlation between the TI and the OR. See Materials and Methods for formulae used to calculate indices.

significant difference in the TI of cells that had predominantly on responses, those that had predominantly off responses, and those that had an even mixture of the 2 . As noted above, cells were equally likely to show suppression regardless of whether they were classified as simple or complex on the basis of whether or not spatially separate on and off subfields could be demonstrated using hand-held stimuli. There was also no correlation between the $\mathrm{TI}$ and the degree of overlap of on and off responses as measured in quantitative tests (data not shown).

Selectivity for stimulus length. The suppression observed in paired-pulse tests was not due to end-inhibition because the stimuli used were adjusted to be optimal for each cell. In a few cells, the length of the condition stimulus was varied and was found to have little effect on the degree of suppression. This issue was not systematically studied, however.

Other receptive field properties. No relationship was found between the presence of suppression and any other receptive field property investigated, such as size, visual field location, or ocular dominance.

Level of anesthesia. At the end of each of 7 experiments, additional doses of barbiturate were given in order to assess the effect of deepening the anesthesia on temporal properties of cortical neurons. Of the 7 cells studied, 5 showed significant paired-pulse suppression, and 2 did not. In each case, administration of 2-6 times the hourly dose of barbiturate depressed overall responsiveness, but did not alter the degree or time course of paired-pulse suppression. 


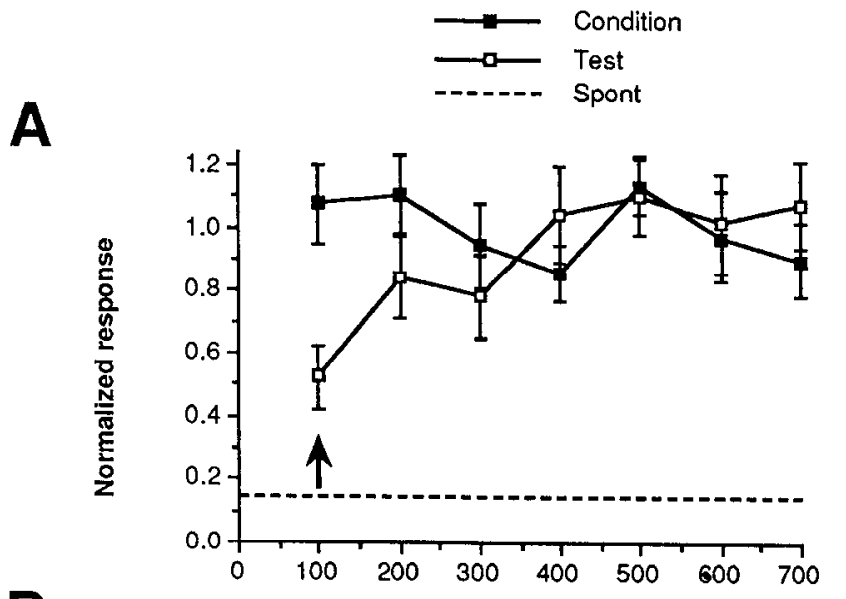

B

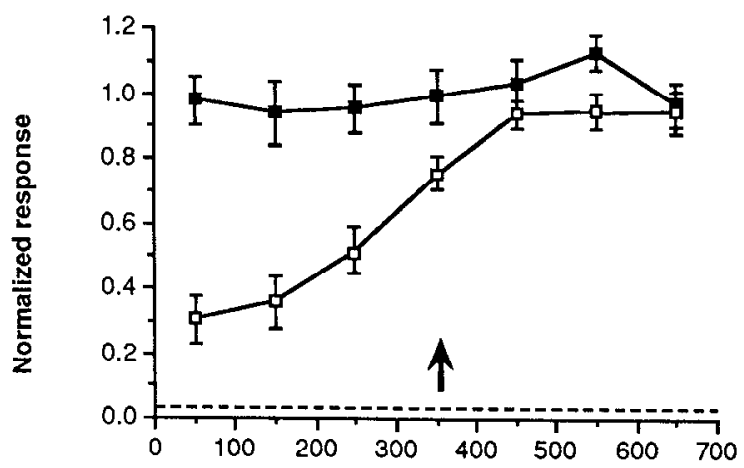

C

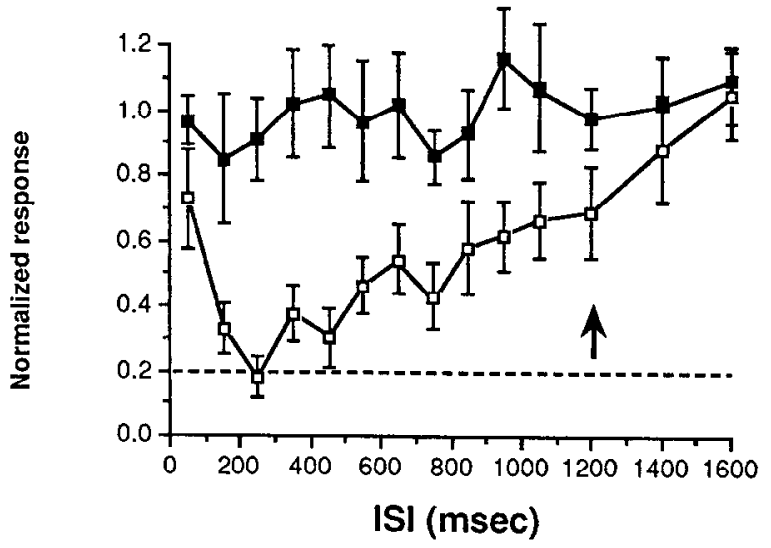

Figure 4. Time course of suppression observed in area 17 neurons. Results from 3 cells $(A, B, C)$ showing short-, medium-, and longduration suppression are shown. Stimuli were pairs of stationary bars of optimal orientation, size, and position that were flashed on for 200 msec. The ISI was varied as indicated by the abscissa. The solid and open symbols indicate the responses to the condition and test stimuli, respectively. Responses in each test are normalized to the mean condition-stimulus response. Error bars indicate the SEM over the 20 repetitions. The dashed line indicates the spontaneous rate. The arrows mark the longest ISI at which the difference between condition and test responses was significant.

\section{Time course of the suppression}

The time course of the suppression was studied in 79 cells in area 17 by varying the ISI between the condition and test stimuli. Most of the cells $(32 / 37 ; 86 \%)$ that did not show suppression at an ISI of $200 \mathrm{msec}$ also failed to show the effect when the ISI was reduced to 100 or $50 \mathrm{msec}$, and none of them showed

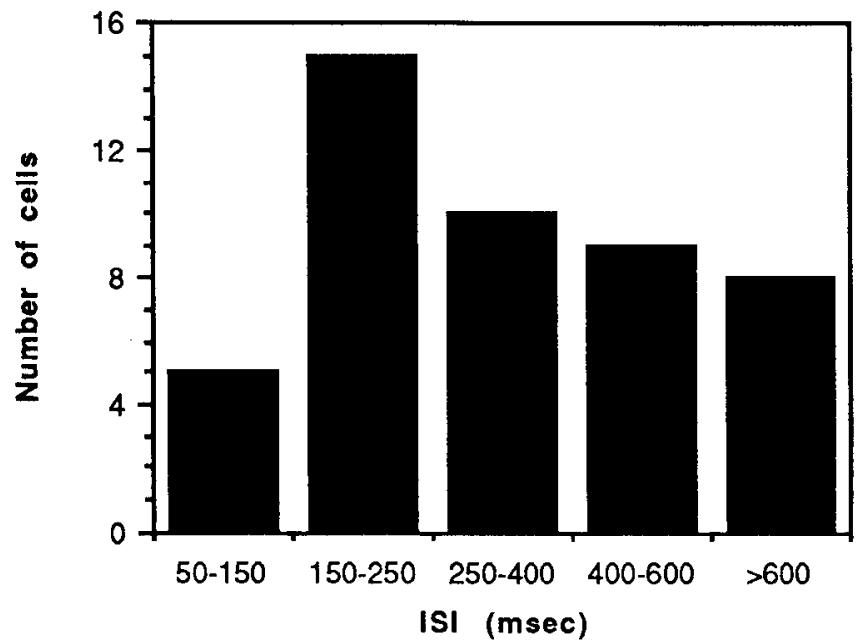

Figure 5. Longest ISI at which suppression was significant: results from 47 neurons that were tested at various ISIs between 50 and $1600 \mathrm{msec}$ (see text and Fig. 4 for further details). Results from 32 additional cells for which suppression was not significant at any ISI are not shown.

suppression at longer ISIs. Many of the cells that did show suppression at $200 \mathrm{msec}$ also showed suppression at longer ISIs. Three examples are shown in Figure 4. In general, suppression was greatest at the shortest ISIs tested and declined roughly exponentially with increasing ISI. The time course varied substantially from cell to cell. In a few cells, the maximum suppression occurred only after a delay of $100-250 \mathrm{msec}$ (see Fig. $4 C$ ). For each of the 47 cells that were tested at a variety of ISIs and that did show significant suppression, the longest ISI at which significant suppression was observed was recorded. These data are shown in Figure 5. The longest ISI at which any cell showed significant suppression was $1200 \mathrm{msec}$.

Three cells that did not show facilitation at $200 \mathrm{msec}$ did show facilitation at longer ISIs. Thus, when cells are tested at a range of ISIs, facilitation may be slightly more common than when cells are tested only at $200 \mathrm{msec}$. Nevertheless, the percentage of cells in area 17 showing facilitation is still quite small $(5 / 79 ; 6.3 \%)$.

A very different picture emerged from similar tests performed in area 18. Figure 6 shows 2 examples. For both of these cells, as for most of the area 18 neurons tested $(23 / 29 ; 79 \%)$, an initial period of suppression was followed by a period of facilitation. Suppression tended to be more short-lived than in area 17. Although 16 of $29(55 \%)$ cells showed a period of significant suppression, in 6 of these cells, the suppression was present only when tested with an ISI of $100 \mathrm{msec}$, and in 3 others, the period of suppression was equally brief but occurred at longer ISIs. Significant facilitation was present in 18 of $29(62 \%)$ neurons tcsted. Facilitation generally lasted longer than suppression, but the end of the period of facilitation was not adequately determined in many cells.

\section{Stimulus specificity}

By varying the nature of the condition stimulus used, it was possible to assess the stimulus specificity of the suppression.

Orientation. The amount of suppression produced by a condition stimulus depended on its orientation. Condition stimuli presented at the cell's preferred orientation evoked maximal suppression, while condition stimuli presented at the orthogonal orientation generally evoked no suppression. An example of this 


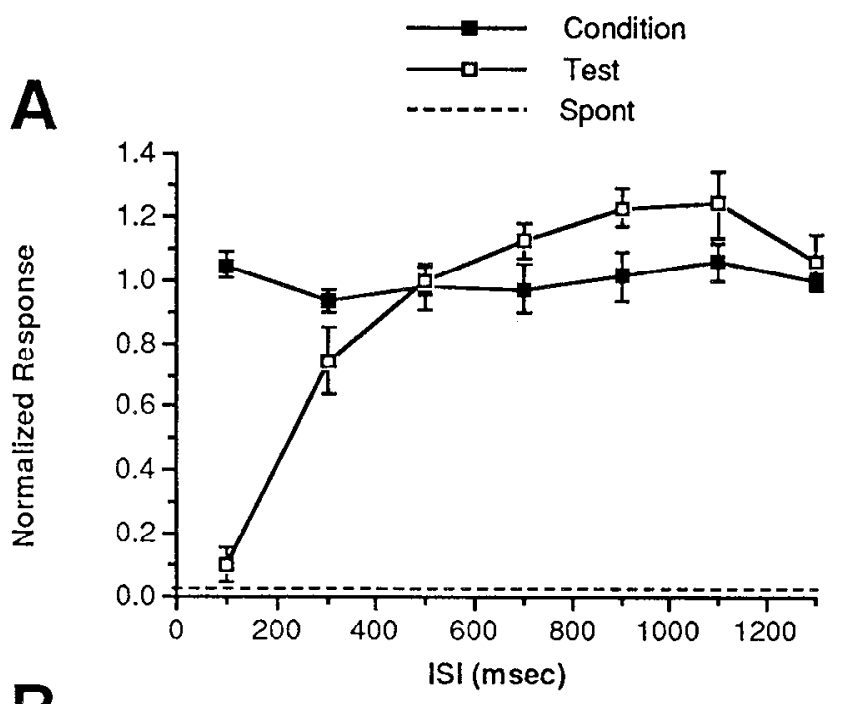

B

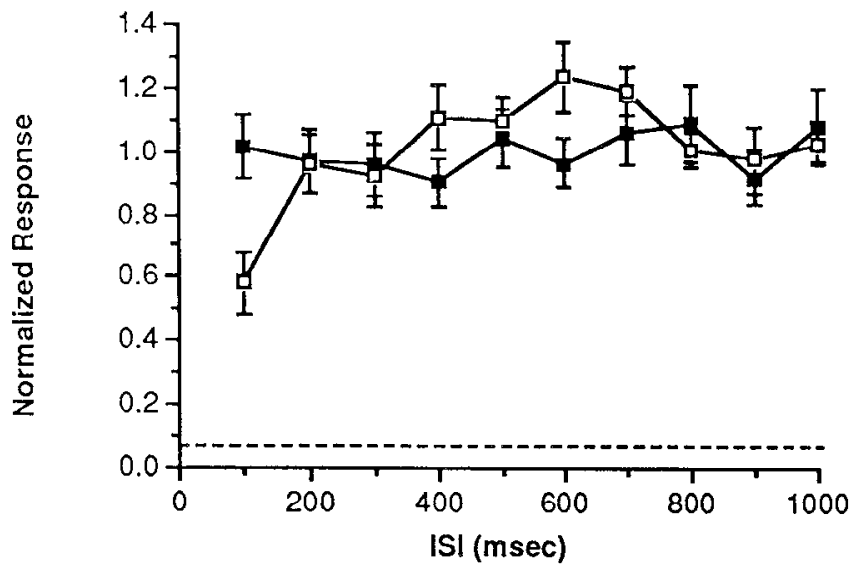

Figure 6. Time course of suppression and facilitation in area 18 neurons: results from 2 cells. The cell shown in $A$ displayed significant suppression at ISIs of 100 and $300 \mathrm{msec}$ and significant facilitation at ISIs of 700-1 $100 \mathrm{msec}$. The cell shown in $B$ displayed significant suppression only at $100 \mathrm{msec}$ and facilitation that reached significance only at $600 \mathrm{msec}$. Conventions are as in Figure 4.

orientation dependence is shown in Figure 7. Note that the distribution of suppression is centered on the preferred orientation, but that it is more broadly tuned than the cell's excitatory response. Similar results were obtained in 22 out of $25(88 \%)$ cells tested in this way. In the remaining 3 cells, weak suppression was present at all orientations. No cell showed greater suppression at the orthogonal orientation than at the preferred orientation.

In order to measure the relative tuning of the excitation and suppression, half-width at half-height was calculated from the 2 curves obtained from each cell. The half-width of the suppression was defined as the angular separation between condition and test stimuli at which the suppression fell to half its maximal value. Figure 8 shows the relationship between excitatory and suppressive half-widths for each of the 25 cells tested (including 2 cells from area 18). The diagonal line indicates equal orientation tuning for excitation and suppression. Most points are above the line, indicating sharper tuning for excitation than for suppression.

In many cells for which a detailed study of the orientation dependence of the suppression was not made, suppression was,

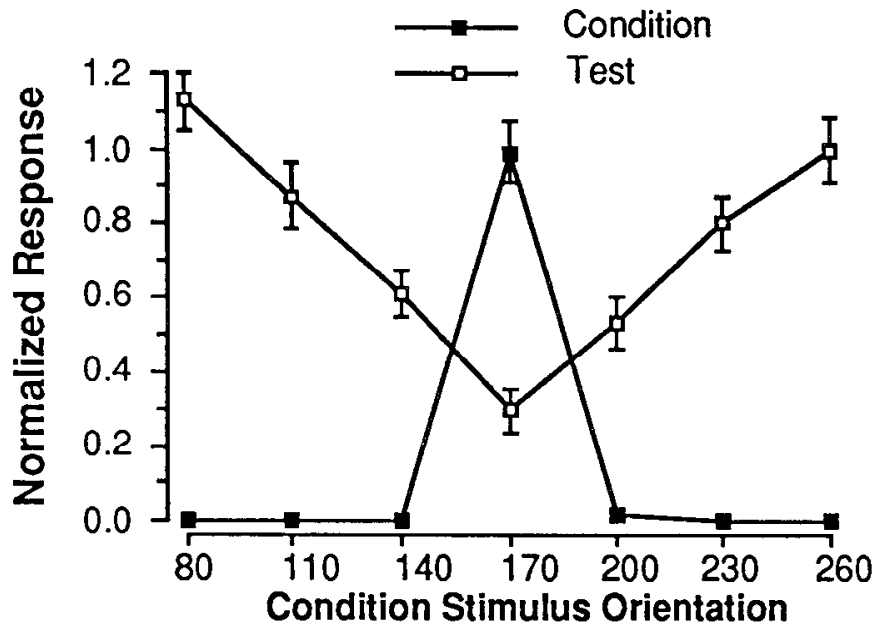

Figure 7. Orientation tuning of suppression. As in previous plots, solid and open symbols indicate the mean responses to the condition and test stimuli, respectively. The test stimulus was always presented at the cell's preferred orientation $\left(170^{\circ}\right)$, but the condition stimulus orientation was varied in $30^{\circ}$ increments. All responses are normalized to that of the condition stimulus presented at the preferred orientation. This cell showed no spontaneous activity. Other conventions are identical to those in Figure 4. Note that the suppression is strongest at the preferred orientation but is also quite strong at adjacent orientations where the condition stimulus evokes no excitatory response.

nevertheless, compared at the preferred and orthogonal orientations. All of these cells showed greater suppression at the preferred orientation. Suppression at the orthogonal orientation was almost always absent.

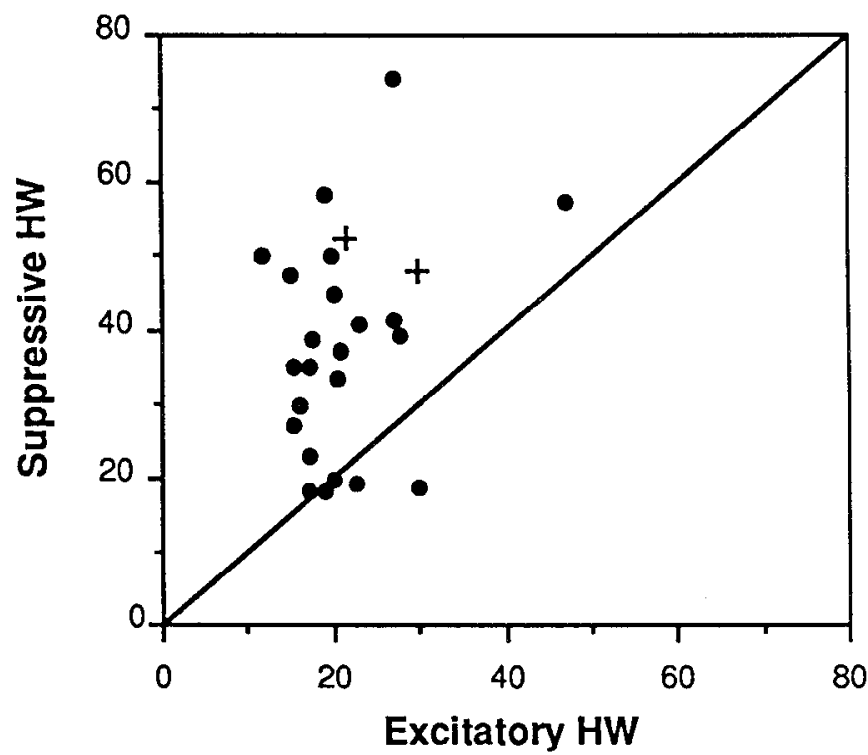

Figure 8. Orientation tuning of excitation and suppression. The orientation dependence of the suppression was assessed in 25 cells by varying the orientation of the condition stimulus while keeping the orientation of the test stimulus constant, as explained in Figure 7. Excitatory half-widths were calculated from the responses to the condition stimuli. Suppressive half-width was defined as the orientation difference between condition and test at which the suppression was half maximal. Solid circles indicate area 17 neurons. Two area 18 neurons are indicated by crosses. In all cells, the maximal suppression occurred at the cell's preferred orientation. Most cells showed broader tuning for suppression than for excitation (points above the diagonal). In a few cells, the degree of tuning was equal or slightly sharper for suppression (points on or below the diagonal). 


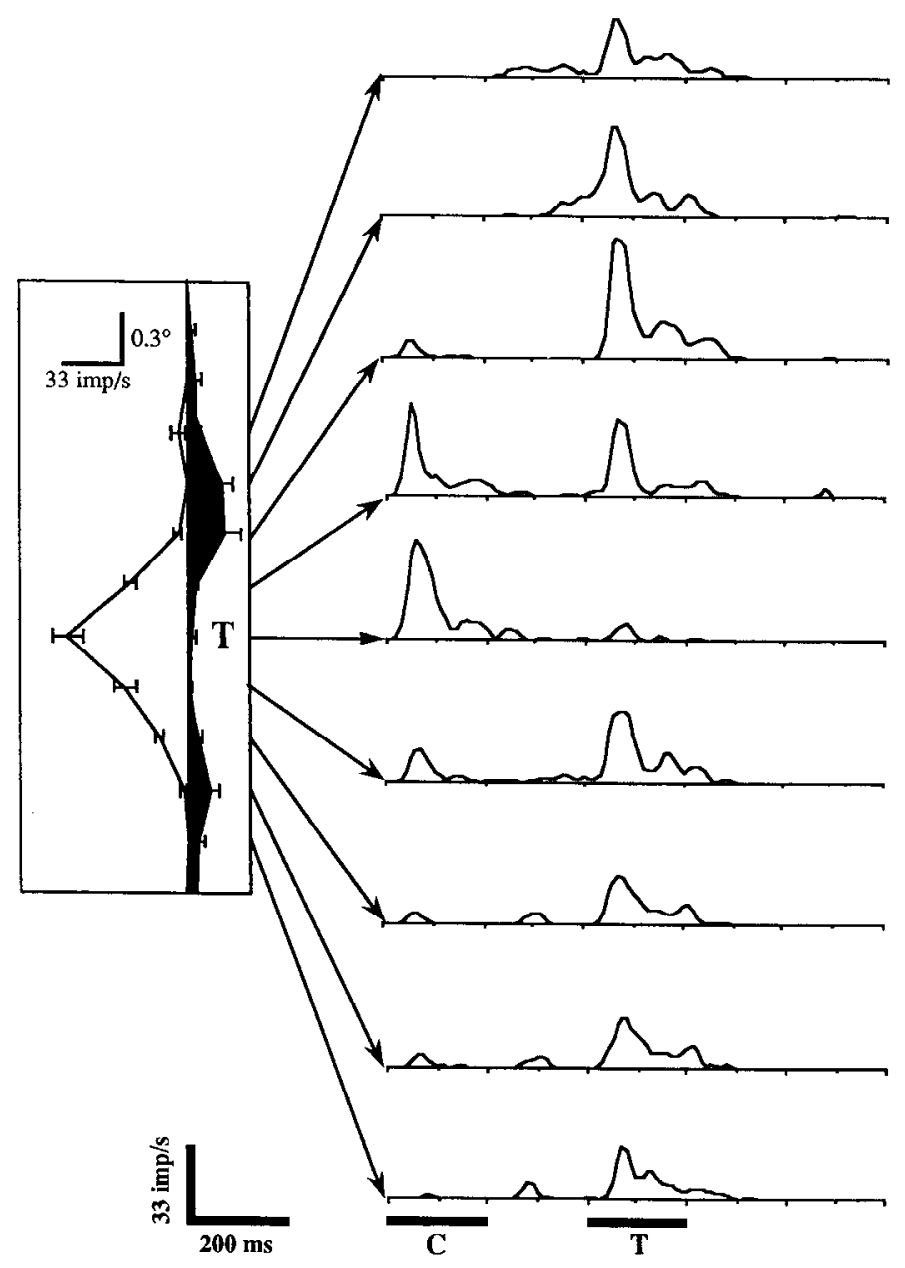

Figure 9. Positional dependence of suppression. A static field plot obtained from an area 17 simple cell is shown on the left. On responses are indicated by the open regions, off responses by solid regions. Calibration is shown in the upper left-hand corner. Smoothed histograms on right show results of a temporal interaction test in which the condition stimulus position was varied in $0.3^{\circ}$ increments. Correspondence between condition stimulus location and locations of static field measurements is indicated by arrows. The test stimulus was always presented at the most responsive region within the receptive field (marked $T$ in static field plot). Responses to the test stimulus varied as a function of the condition stimulus position. Compare each test response to the condition response when presented at the test location (central histogram). Suppression was strongest when the condition and test stimuli were presented at the same location (central histogram). Spatial offset of the condition and test stimuli generated apparent movement. When this movement occurred in the cell's preferred direction (from larger of region to central on region, shown in upper histograms), there was facilitation. When the movement occurred in the opposite direction, there was weak suppression. This cell showed a similar degree of directional preference when tested with moving stimuli. Stimuli were presented for $200 \mathrm{msec}$ each with a $200-\mathrm{msec}$ ISI as indicated by markers at bottom. Responses were summed across 20 repetitions and smoothed using a digital Gaussian filter $(\mathrm{SD}=20 \mathrm{msec})$.

Position. The suppression produced by a condition stimulus was usually highly localized. In order to estimate the spatial extent of the suppression, the position of the condition stimulus was displaced in small increments along the preferred axis of the movement from trial to trial, while the position of the test stimulus remained constant. Figure 9 shows the histograms obtained from such a test. The results of a line-weighting test performed on the same cell are shown along the left-hand side.

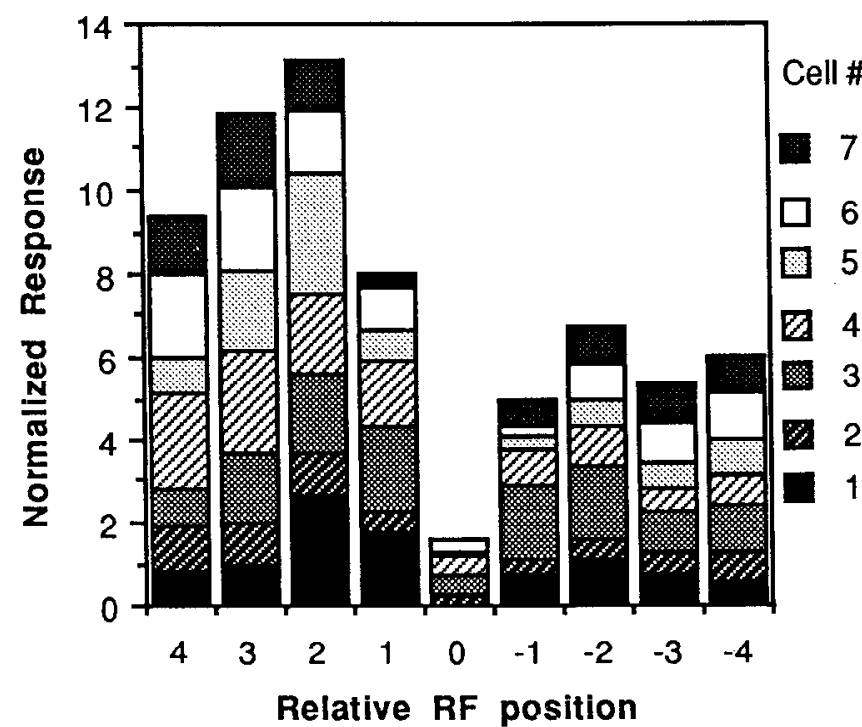

Figure 10. Positional dependence of temporal interactions in directionally selective cells. Seven cells that showed a $2: 1$ or greater directional preference when tested with moving stimuli (DI $<0.5$ ) were tested with condition stimuli presented at 9 different receptive field positions (as in Fig. 9). The distance between neighboring locations was $0.5^{\circ}$ for cells $1-4$ and $0.3^{\circ}$ for cells 5-7. Histograms show the test responses for each cell as a function of the position of the condition stimulus relative to the test location (position 0). Positive positions indicate apparent movement in the preferred direction. Negative positions correspond to movement in the null direction. For each cell, the responses are normalized to the response to the test stimulus presented alone. Note that, though there is some suppression of nonpreferred apparent movement, the suppression is generally strongest when there is no movement. This is true for all of the cells shown except cell 6 , which shows a slightly greater suppression at position -1. All stimuli are $200 \mathrm{msec}$, with a $200-\mathrm{msec}$ ISI.

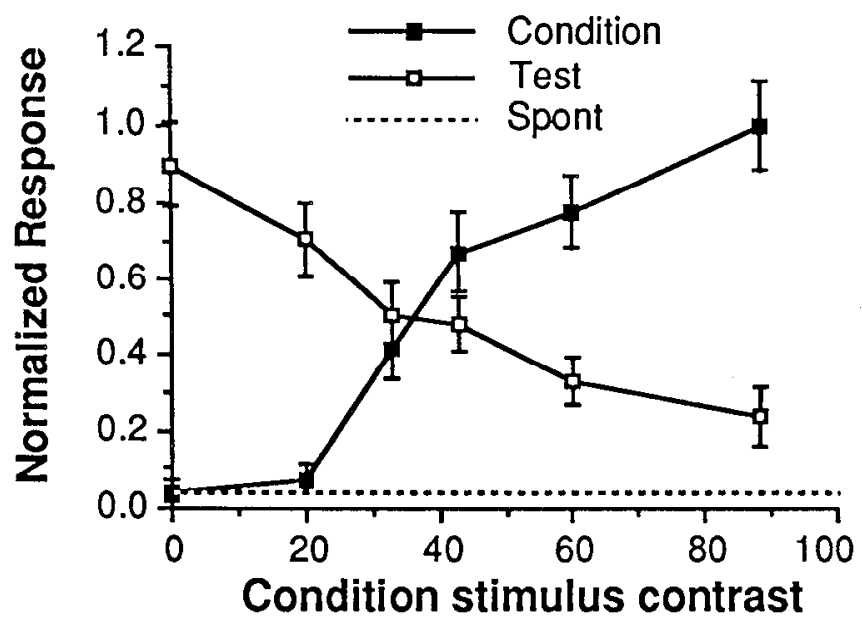

Figure 11. Effects of varying condition stimulus luminance. The luminance of the condition stimulus was varied between 0.5 and $8.0 \mathrm{~cd} /$ $\mathrm{m}^{2}$, while the luminance of the background remained $0.5 \mathrm{~cd} / \mathrm{m}^{2}$. The test stimulus was always presented at $8.0 \mathrm{~cd} / \mathrm{m}^{2}$. The data are plotted in terms of stimulus contrast rather than luminance because other experiments indicate that identical suppression results from similar contrast stimuli that differ in mean luminance (data not shown). Responses are normalized to the condition stimulus response at the highest contrast used (88\%). All other conventions are as in Figure 4 . Note that the degree of observed suppression increases roughly linearly with contrast. 
A

1.0

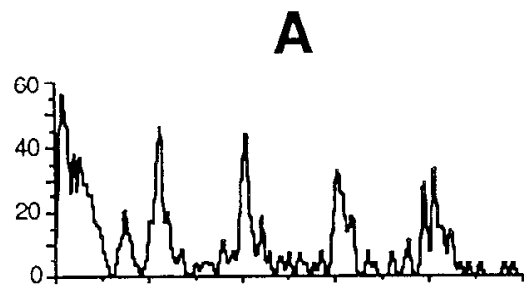

2.1

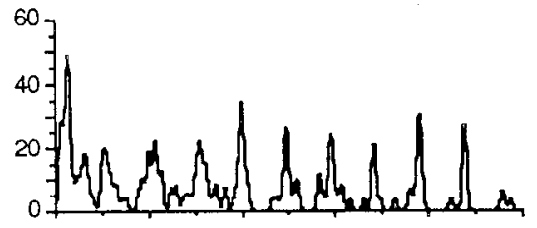

4.2

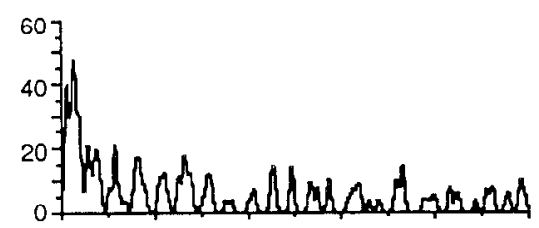

10.0

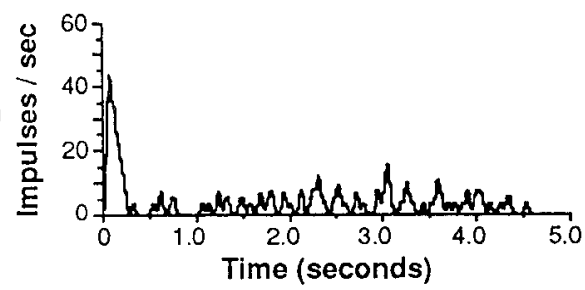

B
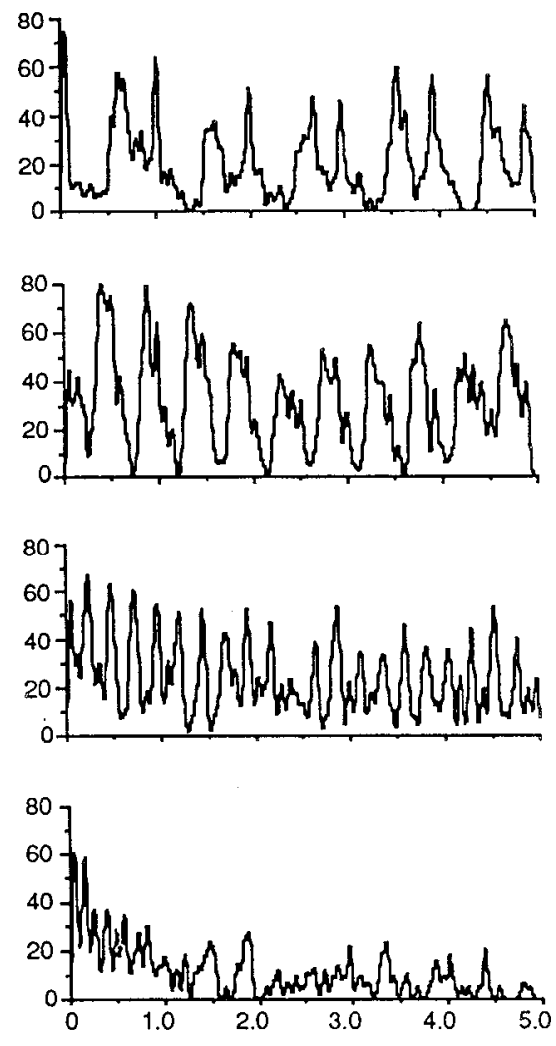

Figure 12. Effects of repetitive stimulation. Results from 2 cells each stimulated with stationary bars flashed on and off at 4 different frequencies. Responses were summed over 5 repetitions and smoothed with a digital Gaussian filter (SD $-20 \mathrm{msec}$ ). For each plot, the spike rate is shown on the ordinate, and time in msec is shown on the abscissa. $A$, A simple cell that showed significant suppression in a temporal interaction test. Note that the response adapts slowly at $\mathrm{l} \mathrm{Hz}$, and that the rate and depth of the adaptation increases as the frequency is raised. $B$, A complex cell that did not show suppression in a temporal interaction test. Note the absence of adaptation at low frequencies ( 1 and $2 \mathrm{~Hz}$ ) but pronounced adaptation at $10 \mathrm{~Hz}$.
In the central histogram (marked " $T$ "), the condition and test stimuli were presented at the same location within the on subfield of this simple cell. In each of the histograms below the central one, the condition stimulus was moved successively further from the test location in $0.3^{\circ}$ increments (the widths of the stimuli were also $0.3^{\circ}$ ). In each of the histograms above the central one, the condition stimulus was also moved, but in the opposite direction. The position of the test stimulus remained constant. Only when the condition and test stimuli are presented at the same location does the suppression occur.

These stimuli are very similar to the apparent-motion stimuli used by others to probe the mechanisms of dircction sclcctivity in cortical neurons (Emerson and Gerstein, 1977; Baker and Cynader, 1986; Emerson et al., 1987). Closer inspection of the responses shown in Figure 9 reveals a directional asymmetry. The test response was somewhat depressed when displacement was in the nonpreferred direction (lower histograms), and it was enhanced for displacements in the preferred direction (upper histograms). The cell's response to moving stimuli (not shown) showed a comparable asymmetry. In other cells, the responses to the 2 directions of displacement were even more asymmetric. Results from 7 directional (DI $<0.5$ ) cells are shown in Figure 10. The observed asymmetry was due both to suppression of responses in the null direction and to enhancement of responses in the preferred direction. In all cases, there was good agreement between the asymmetry seen with stationary stimuli and the preferred direction observed with moving stimuli. In most of the cells tested in this way $(16 / 19 ; 84 \%)$, the suppression was strongest when the condition and test stimuli coincided. In the remaining 3 cells, the suppression was greatest for apparent motion in the nonpreferred direction, but in each case, the degree of suppression was only slightly greater (within 1 SD) than when the condition and test coincided.

The strength and duration of the suppression often varied substantially from one receptive field region to another. In general, off responses showed less suppression than on responses. This may reflect an asymmetry in the way such responses were measured. Off responses were sometimes measured using dark bars but were more frequently measured after the offset of a light bar. These 2 types of stimulation may not be equivalent.

Contrast. The suppression produced by a masking stimulus was specific to the sign of the contrast of that stimulus; that is, a light bar suppressed the response to the onset of a light bar but not to its offset or to the onset of a dark bar. This was true not only of simple cells in which on and off responses are spatially separated, but also of complex cells.

The effect of varying the magnitude of the condition stimulus contrast was investigated in 15 cells. In each case, the suppression was greatest at the highest contrasts used. Figurc 11 shows an example. The response to the condition stimulus varied roughly sigmoidally with contrast. The test stimulus was always presented at the highest contrast $(88 \%)$. The degree of suppression increased roughly linearly with condition stimulus contrast.

Duration. Fourteen cells were tested with condition stimuli that varied in duration between 50 and $750 \mathrm{msec}$. In general, the effectiveness of the condition stimulus in producing suppression increased as its duration was increased from 50 to 200 msec, but further increases in duration produced no further changes in the evoked suppression. In a few cells, maximal suppression was achieved with briefer stimuli, and in 2 cells, 
suppression was maximal only for condition stimulus durations of $300 \mathrm{msec}$ or more.

\section{Effects of repetitive stimulation}

Forty-nine cells were also tested with stationary stimuli that were flashed on and off at various temporal frequencies. In general, low frequencies of stimulation ( $1 \mathrm{~Hz}$ or below) produced no decrement in response over the course of 5-10 sec of stimulation. As the frequency of stimulation was raised, however, the response of the cell adapted. The rate at which this adaptation occurred increased with increasing frequency. Figure 12 shows the responses of 2 cells to 4 different frequencies of stimulation. The cell shown in Figure $12 A$ was a simple cell that did show significant suppression in a temporal interaction test. For this cell, even stimulation at $1 \mathrm{~Hz}$ produced weak adaptation. Stimulation at progressively higher rates increased the rate and depth of the adaptation. The cell shown in Figure $12 B$ was a complex cell that did not show appreciable suppression when tested with pairs of stimuli. This cell showed only weak adaptation at $4 \mathrm{~Hz}$, and no adaptation at lower frequencies. Increasing the rate of stimulation to $10 \mathrm{~Hz}$. caused more pronounced adaptation. Adaptation tended to be more rapid and powerful for cells that showed paired-pulse suppression, but even cells that did not show appreciable suppression when tested with pairs of stimuli showed adaptation when tested with higher frequency trains of stimuli. It was also often the case that 2 cells showing the same degree of paired-pulse suppression showed different degrees of adaptation.

\section{Discussion}

The results of this study have demonstrated the existence of powerful local suppressive mechanisms that are tuned for stimulus orientation. The observed suppression has many of the features of the lateral inhibition proposed by Carpenter and Blakcmorc (1973) and others: It is maximal at the preferred orientation but is broadly tuned, it is highly localized within the receptive field, it increases with increasing contrast, it does not require long exposures, and it can outlast the stimulus that evokes it by many hundreds of milliseconds.

\section{The distribution of cells showing suppression}

Although the strength and time course of the suppression varied widely, some degree of response reduction was present in nearly all of the cells studied. In many cells, the reduction was weak enough and/or the responses of the cell were variable enough that the adopted criteria for statistical significance were not met. It is likely that, given a larger number of stimulus repetitions, some of these cells would have showed significant suppression. When considered as a group, however, even the cells that did not individually show significant changes did show a significant trend toward suppression.

The amount of suppression observed was not constant throughout the depth of the cortex. Outside of layer 5 , about $2 / 3$ of the cells showed significant suppression. Within layer 5 , suppression was less common. One possible explanation for this is that layer 5 cells may have much higher contrast gains than other cells and hence may respond maximally even to a stimulus whose effectiveness has been reduced by a prior condition stimulus. This explanation assumes that a condition stimulus causes a decrease in the effective contrast of a subsequent test stimulus, in much the same way as does an adapting stimulus during contrast adaptation (Georgeson and Georgeson, 1987). Special complex cells, most of which are located in layer 5 (Gilbert, 1977), have substantially lower thresholds and higher gains for contrast than other cortical cells, and their responses saturate at much lower contrasts (Dean, 1981). The contrast at which responses of these cells saturate may be lower than the effective contrast of the test stimuli used.

Suppression was also less marked within area 18. Because suppression might be expected to limit a cell's response to higher temporal frequencies, it is perhaps not surprising that area 17 neurons, which are generally tuned to lower temporal frequencies than area 18 neurons (Movshon et al., 1978; Vidyasagar and Heide, 1986), show more pronounced suppression. Area 18 cells also showed much more pronounced facilitation than did area 17 neurons. Further study will be required to adequately assess the mechanism and function of this facilitation. However, it is worth noting that psychophysical studies of paired-pulse stimulation have uncovered facilitatory as well as suppressive effects (Bachman, 1988).

\section{Possible effects of anesthesia}

All of the experiments were performed using barbiturate anesthesia, a factor that may have influenced the observed temporal interactions. Barbiturate is known to enhance inhibitory GABAergic transmission and may also have additional nonspecific effects. There are several reasons for believing that this was not a major factor determining the degree of suppression observed. First, additional doses of anesthetic did not enhance suppression or reveal it in cells that did not show it previously. Second, in each penetration, both cells that did and cells that did not show suppression were encountered, while the delivery of anesthetic remained constant. Third, 2 previous studies, by Judge et al. (1980) in the awake behaving monkey and by Kaji et al. (1983) in the Fluothane- and $\mathrm{N}_{2} \mathrm{O}$-anesthetized cat, have demonstrated similar suppressive effects. Finally, the possibility that barbiturate causes or enhances paired-pulse suppression by enhancing GABA-mediated chloride currents is contradicted by the observation presented in an accompanying paper (Nelson, 1991b) that paired-pulse suppression persists in the presence of the GABA blocker bicuculline.

\section{The orientation dependence of the suppression}

Suppression was always strongest at the cell's preferred orientation and, in nearly all cells, was absent at the orthogonal orientation. In most of the cells tested, the orientation tuning of the suppression was quite broad. The present study employed stimuli that differed in orientation by multiples of $30^{\circ}$. While it is true that the sharpness of the orientation tuning of excitatory responses may have been underestimated by the use of broadly spaced stimuli, this is true only for those cells with tuning curve half-widths of $15^{\circ}$ or less. Because no cells had an apparent inhibitory tuning this sharp, this is unlikely to have been a problem for the inhibitory responses. Very sharply tuned suppressive interactions would have been missed only if they occurred at some orientation other than that preferred by the cell, but in fact, it was consistently observed that suppression was strongest at the preferred orientation.

The present results are concordant with those of a previous study by Kaji et al. (1983), which also described broadly tuned inhibitory interactions in the responses of cat visual cortical neurons to pairs of slits. The orientation dependence of the suppression observed in this study also matches that of the lateral inhibition envisaged by Carpenter and Blakemore (1973) 
and others. Results of recent intracellular recordings have confirmed the idea that inhibition is maximal at the cell's preferred orientation, but have failed to uncover a broader tuning for inhibition than for excitation (Ferster, 1986). This latter result may reflect the fact that quantitative testing of the orientation half-widths of IPSPs was not performed, or it may reflect a true discrepancy between intracellularly recorded inhibition and the suppression recorded extracellularly or inferred from psychophysical studies.

The orientation tuning of the suppression demonstrated in this study is also remarkably similar to that of the surround effect (Blakemore and Tobin, 1972; Fries et al., 1977; Nelson and Frost, 1978). This effect differs from the suppression observed in this study both in its time course and in its spatial distribution: The surround effect is spatially more diffuse and temporally more restricted. It should be pointed out, however, that the time course of the surround effect has been reported only for 1 cell (Nelson and Frost, 1978). It would be interesting to know whether or not longer-lasting effects of surround stimulation also occur.

The present findings are clearly not indicative of the kind of cross-orientation inhibition proposed by Morrone et al. (1982). Like the present study, many of the studies that provided evidence for the cross-orientation model involved interactions between 2 differently oriented stimuli (Bishop et al., 1971; Morrone et al., 1982). A major difference between those studies and this one, however, is that stimuli were presented simultaneously in previous studies and consecutively in this one. The use of consecutive stimuli may miss inhibitory interactions that occur with a more rapid time course. On the other hand, simultaneous stimuli may evoke excitatory interactions that were relatively uncommon in the present study. Several lines of evidence suggest that excitatory interactions occur predominantly between cells of similar orientation (for review, see LeVay, 1988). Hence, the presence of excitatory interactions near a cell's preferred orientation might bias the observed distribution of suppression away from that orientation. Also, as suggested by Ferster and Koch (1987), presentation of 2 slits simultaneously may lead to inhibitory effects occurring at the level of the lateral geniculate nucleus (LGN). They argue that, when LGN cells are stimulated with 2 bars that differ in orientation, there will be increased inhibition from the receptive field surround that could give rise to suppression in cortical neurons that appears strongest at orientations other than that preferred by the cell. Interestingly, Kaji et al. (1983) found just this pattern of suppression when cortical cells were stimulated with simultaneous slits, but found suppression centered on the preferred orientation when successive slits were used. Presumably, in the successive case, the more short-lived LGN effects (see Nelson, 1991a) have subsided by the time the test stimulus is presented.

\section{The time course of the observed suppression}

A number of psychophysical phenomena that have been attributed to lateral inhibition may be due to the physiological suppression observed in this study. Principal among these is the tilt aftereffect. Harris and Calvert (1989) recently demonstrated that large tilt aftereffects could be obtained using stimuli that were similar in duration and ISI to those used in the present study. Another study of induced tilt found that the effects of the inducing stimulus decayed to baseline over the course of several hundred msec (Matin, 1974). In other studies of induced tilt, however, very different time courses have been obtained. Some reports indicate that the simultaneous tilt illusion can occur very quickly (Wolfe, 1984; Calvert and Harris, 1988), while other reports suggest that some degree of tilt aftereffect can last for hours or even days (Wolfe, 1986). An important question for further work is precisely how these effects occurring at various time courses are related to each other.

In addition to changing the apparent orientation of a subsequent test stimulus, a condition stimulus can alter its visibility. When measured over brief time courses, the effect is referred to as masking. Longer-lasting effects are usually referred to as adaptation. Masking measured psychophysically generally has a shorter timc course than does the suppression observed in this study (Georgeson and Georgeson, 1987). This may reflect differences in the duration, luminance, and spatial profile of the masking stimuli used. Only a few studies have looked at the forward masking effects of stimuli presented at various orientations. In contrast, the orientation selectivity of adaptation has been well studied and appears to match the current results quite well. Adaptation typically has a decay-time constant that is substantially longer than the suppression observed in this study following brief stimuli. Recent psychophysical results in several laboratories have suggested that the duration of the contrast threshold elevation depends on the duration of the adapting stimulus: Brief stimuli cause brief maskinglike effects, while longer stimuli are required to produce the more prolonged effects more typically associated with adaptation (Rose and Lowe, 1982; Georgeson and Georgeson, 1987; Georgeson, 1988; Harris and Calvert, 1989). Masking and adaptation can thus be seen as 2 ends of a continuum, rather than as entirely independent effects. They may reflect 2 separate physiological consequences of cortical inhibition, or they may depend on entirely different mechanisms, but in either case, presumably any given stimulus evokes a mixture of the 2 processes.

It was found in the present study that, in addition to the suppressive effects evoked by a single brief stimulus, cells show suppression that develops more slowly during the course of repetitive stimulation. Although the duration and stimulus dependency of this suppression have not been studied in detail, it seems likely that the effect is identical to the adaptation effects that have been demonstrated in several other physiological studies (Maffei et al., 1973; Ohzawa et al., 1982) and that are assumed to underlie contrast adaptation measured psychophysically. The strength and rate of the adaptation found in the present study dcpended on the temporal frequency of the stimulation. This type of behavior has been noted before for neurons in the superior colliculus (Oyster and Takahashi, 1974) and in at least one psychophysical study (Smith, 1971), but has not been adequately studied in cortical neurons. The observed adaptation does not appear to be accountable purely in terms of a buildup of paired-pulse suppression, because even cells that showed no paired-pulse suppression showed adaptation. Rather, it seems the 2 processes have a similar effect but are complimentary in time course: The paired-pulse suppression can be initiated by a brief stimulus and lasts less than a second, while adaptation develops more slowly and lasts longer.

There are, of course, important differences between the present study and the psychophysical studies of masking and adaptation described above. Many of these studies used grating stimuli rather than the bars used in the present study. Also, in most psychophysical studies, the eyes of the subjects are free to move (even if only the small movements that occur during fixation). Finally, and perhaps most importantly, there is always 
a great deal of uncertainty in attempting to relate the physiology of the cat's visual cortex to the perception of humans.

\section{The positional dependence of the suppression}

Suppression was found to be highly localized within the receptive field. Responses to stimuli that were displaced spatially were often not suppressed even if they fell within the same subfield. Functionally, this means that the responses to moving stimuli will selectively escape the suppression. In directional cells, the suppression is anisotropic, a finding that is consistent with several previous physiological studies of apparent motion (Emerson and Gerstein, 1977; Baker and Cynader, 1986; Emerson et al., 1987). However, suppression was almost always strongest when there was no displacement between the condition and test stimuli. Thus, the suppression is more effective in reducing the response to nonmoving stimuli than it is in reducing the response to stimuli moving in the nonpreferred direction.

As noted above, the spatial layout of the suppression observed in this study is quite different from that reported for the surround effect. Perhaps the surround effect reflects the ability of longrange intracortical connections to drive a more local inhibitory mechanism. Activation of the inhibitory mechanism might be expected to require more intense stimulation of the periphery than would be required for stimulation of the receptive field center. If so, a single bar placed in the surround might be less effective than a large grating. Psychophysical studies of induced tilt in geometric illusions have demonstrated that the strength of the tilt increases both with decreasing distance between inducing and test stimuli and with increasing numbers of inducing elements (Wallace, 1969; Wallace and Crampin, 1969).

\section{Mechanism of the suppression}

One possible explanation for the observed suppression is that the cell is fatigued by the condition stimulus. The observation, however, that substantial suppression could be evoked by nonoptimally oriented stimuli that failed to cause an excitatory response is strong evidence against this idea.

A second possibility is that the suppression arises at an earlier stage of the visual system. Results from recordings obtained in the LGN indicate that geniculate neurons do not show suppression that could account for that observed in the cortex (Nelson, 1991a). It should be pointed out, however, that the suppression could occur at the geniculocortical synapse or result from biophysical properties of the dendrites of cortical neurons (e.g., a long-lasting potassium conductance). Both of these sites are, in a sense, antecedent to the site at which the responses of cortical neurons are usually obtained. These possibilities could be properly investigated only by intracellular recording.

The third possibility is that paired-pulse suppression is due to intracortical inhibition of the type originally proposed by Carpenter and Blakemore (1973) and others. If the suppression reflects a lateral inhibitory mechanism, it is probably a mechanism that is slower than the intracortical inhibition mediated by the bicuculline-sensitive $\mathrm{GABA}_{\mathrm{A}}$ receptor. Many cells showed suppression that outlasted the condition stimulus by hundreds of milliseconds. By contrast, "fast," bicuculline-sensitive IPSPs generally last only a few milliseconds (Ferster, 1986). More direct evidence that $\mathrm{GABA}_{\mathrm{A}}$-mediated inhibition is not responsible for the suppression is presented in an accompanying paper (Nelson, 1991b). One possibility is that the suppression is mediated by another inhibitory receptor (e.g., like the GABA $_{B}$ receptor). It is tempting to speculate that the immediate, brief (hundreds of milliseconds), and prolonged (seconds, minutes, or longer) suppressive effects demonstrated in studies of illusions, masking, and adaptation result from different phases of the same underlying process. For example, one might imagine that activating a lateral inhibitory network could cause fast GA$\mathrm{BA}_{\mathrm{A}}$-mediated inhibition, followed by slower $\mathrm{GABA}_{\mathrm{B}}$-mediated inhibition. This latter inhibition might involve both inhibitory conductances lasting several hundreds of milliseconds (Dutar and Nicholl, 1988), as well as more prolonged changes resulting from second-messenger activation. $\mathrm{GABA}_{\mathrm{B}}$ receptors are also reported to have presynaptic effects (Bowery et al., 1980; Thompson and Gähwiler, 1989). Evidence supporting a presynaptic mechanism for paired-pulse suppression is presented in an accompanying paper (Nelson, 1991b).

\section{Function of the suppression}

If the suppression does reflect a form of lateral inhibition, what is its functional role? It has usually been assumed that the function of the lateral inhibition in the cortex is to sharpen the orientation selectivity of single neurons. While the possibility that the suppressive mechanism demonstrated in this study serves this role cannot be ruled out, it seems unlikely, given the lack of correlation between sharpness of orientation tuning and the strength of suppression.

Inhibition is also believed to play an important role in establishing direction selectivity (Sillito, 1977). Unlike the inhibition that would be required to confer directional tuning, however, paired-pulse suppression was almost always strongest when there was no displacement between the 2 stimuli. Also, the suppression is equally likely to be present in nondirectional cells. These results suggest that, though the suppression may enhance the directional selectivity of some cells, this is unlikely to be its major function. Instead, these data suggest that suppression is a basic feature of area 17 neurons, which makes them selectively less sensitive to rapid variations in their inputs that do not arise from movement. In directional cells, this basic feature may have been modified so as to also selectively attenuate nonpreferred movement. Alternatively, paired-pulse suppression and directional suppression may arise from different mechanisms.

Psychophysical and physiological studies of contrast adaptation have suggested that the function of such adaptation is to prevent saturation of cortical neurons by reducing their sensitivity in response to high-contrast stimuli (Ohzawa et al., 1982; Greenlee and Heitger, 1988). Perhaps the major function of paired-pulse suppression is to provide a similar "gain control" operating over a more rapid time course. In addition to this perceptual role, suppression may serve an important biological function. The existence of powerful suppressive mechanisms in the cortex may dampen recurrent excitation, which would otherwise lead to instability. Given the prominence of excitatory, reciprocal connections betwecn the cortcx and LGN and between nearby cortical cells, it is not hard to imagine that a variety of suppressive mechanisms, perhaps operating over different time courses, may be required to prevent positive feedback and runaway excitation.

\section{References}

Andrews DP (1967) Perception of contour orientation in the central fovea. Part I: short lines. Vision Res 7:975-997.

Bachman T (1988) Time course of the subjective contrast enhancement for a second stimulus in successively paired above-threshold transient forms: perceptual retouch instead of forward masking. Vision Res 28:1255-1261. 
Baker CL, Cynader MS (1986) Spatial receptive-field properties of direction-selective neurons in cat striate cortex. J Neurophysiol 55: $1136-1152$.

Bishop PO, Coombs JS, Henry GH (1971) Interaction effects of visual contours on the discharge frequency of simple striate neurons. J Physiol (Lond) 219:659-687.

Blakemore C, Campbell FW (1969) On the existence of neurones in the human visual system selectively sensitive to the orientation and size of retinal images. J Physiol (Lond) 203:237-260.

Blakemore C, Tobin EA (1972) Lateral inhibition between orientation detectors in the cat's visual cortex. Exp Brain Res 15:439-440.

Blakemore C, Carpenter RHS, Georgeson MA (1970) Lateral inhibition between orientation detectors in the human visual system. Nature 228:37-39.

Bouma H, Andriessen JJ (1970) Induced changes in the perceived orientation of line segments. Vision Res 10:333-349.

Bowery NG, Hill DR, Hudson AL, Doble A, Middlemiss J, Shaw J, Turnbull M (1980) (-)Baclofen decreases neurotransmitter release in the mammalian CNS by an action at a novel GABA receptor. Nature 283:92-94.

Calvert JE, Harris JP (1985) Tilt illusion decreases as presentation time increases. Perception 14:A29.

Calvert JE, Harris JP (1988) Spatial frequency and duration effects on the tilt illusion and orientation acuity. Vision Res 28:1051-1059.

Carpenter RHS, Blakemore C (1973) Interactions between orientations in human vision. Exp Brain Res 18:287-303.

Creutzfeldt OD, Kuhnt U, Benevento LA (1974) An intracellular analysis of visual cortical neurones to moving stimuli: responses in a cooperative network. Exp Brain Res 21:251-274.

Dealy RS, Tolhurst DJ (1974) Is spatial adaptation an aftereffect of prolonged inhibition? J Physiol (Lond) 241:261-270.

Dean A (1981) The relationship between response amplitude and contrast for cat striate cortical neurones. J Physiol (Lond) 318:413427.

Dutar P, Nicholl RA (1988) A physiological role for GABA-B receptors in the central nervous system. Nature 332:156-158.

Emerson RC, Gerstein GL (1977) Simple striate neurons in the cat. II. Mechanisms underlying direction asymmetry and direction selectivity. J Neurophysiol 40:136-155.

Emerson RC, Citron MC, Vaughn WJ, Klein SA (1987) Nonlinear directionally selective subunits in complex cells of cat striate cortex. J Neurophysiol 58:33-65.

Ferster D (1986) Orientation selectivity of synaptic potentials in neurons of cat visual cortex. J Neurosci 6:1284-1301.

Ferster D (1987) Origin of orientation-selective EPSPs in simple cells of cat visual cortex. J Neurosci 7:1780-1791.

Ferster D, Koch C (1987) Neuronal connections underlying orientation selectivity in cat visual cortex. Trends Neurosci 10:487-492.

Fries W, Albus K, Creutzfeldt OD (1977) Effects of interacting visual patterns on single cell responses in cat's striate cortex. Vision Res 17: $1001-1008$.

Georgeson MA (1973) Spatial frequency selectivity of a visual tilt illusion. Nature 245:43-45.

Georgeson MA (1988) Spatial phase dependence and the role of motion detection in monocular and dichoptic forward masking. Vision Res 28:1 193-1205.

Georgeson MA, Georgeson JM (1987) Facilitation and masking of briefly presented gratings: time-course and contrast dependence. Vision Res 27:369-379.

Gilbert CD (1977) Laminar differences in receptive field properties of cells in cat primary visual cortex. J Physiol (Lond) 268:391-421.

Greenlee MW, Heitger F (1988) The functional role of contrast adaptation. Vision Res 27:245-255.

Greenlee MW, Magnussen S (1988) Interactions among spatial frequency and orientation channels adapted concurrently. Vision Res 28:1303-1310.

Harris JP, Calvert JE (1989) Contrast, spatial frequency and test duration effects on the tilt aftereffect: implications for underlying mechanisms. Vision Res 29:129-135.

Hubel DH (1957) Tungsten microelectrode for recording from single units. Science 125:549-550.

Judge SJ, Wurtz RF, Richmond BJ (1980) Vision during saccadic eye movements. I. Visual interactions in striate cortex. J Neurophysiol 43:1133-1155.

Kaji S, Yamane S, Kawabata N (1983) Neural interactions of two slits in the orientation domain in the visual cortical units of the cat. Vision Res 23:883-886.

Klein S, Stromeyer CF III, Ganz L (1974) The simultaneous spatial frequency shift: a dissociation between the detection and perception of gratings. Vision Res 14:1421-1432.

Kurtenbach W, Magnussen S (1981) Inhibition, disinhibition and summation among orientation detectors in human vision. Exp Brain Res 43:193-198.

LeVay S (1988) The patchy intrinsic projections of visual cortex. Prog Brain Res 75:147-161.

Maffei L, Fiorentini A, Bisti S (1973) Neural correlate of perceptual adaptation to gratings. Science 182:1036-1038.

Magnussen S, Kurtenbach W (1980) Linear summation of tilt illusion and tilt aftereffect. Vision Res 20:39-42.

Matin E (1974) Light adaptation and the dynamics of indured tilt. Vision Res 14:255-265.

Morrone MC, Burr DC, Maffei L (1982) Functional implications of cross-orientation inhibition of cortical visual cells. 1. Neurophysiological evidence. Proc R Soc Lond [Biol] 216:335-354.

Movshon JA, Thompson ID, Tolhurst DJ (1978) Spatial and temporal contrast sensitivity of neurones in areas 17 and 18 of the cat's visual cortex. J Physiol (Lond) 283:101-120.

Nelson Jl (1985) The cellular basis of perception. In: Models of the visual cortex (Rose D, Dobson VG, eds), pp 108-122. Chichester: Wiley.

Nelson JI, Frost BJ (1978) Orientation-selective inhibition from beyond the classic visual receptive field. Brain Res 139:359-365.

Nelson SB (1991a) Temporal interactions in the cat visual system. II. Suppressive and facilitatory effects in the lateral geniculate nucleus. J Neurosci 11:357-368.

Nelson SB (1991b) Temporal interactions in the cat visual system. III. Pharmacological studies of cortical suppression suggest a presynaptic mechanism. J Neurosci 11:369-380.

Nikara T, Bishop PO, Pettigrew JD (1968) Analysis of retinal correspondence by studying receptive fields of binocular single units in cat striate cortex. Exp Brain Res 6:353-372.

O'Toole B (1979) Exposure-time and spatial-frequency effects in the tilt illusion. Perception 8:557-564.

O'Toole B, Wenderoth P (1977) The tilt illusion: repulsion and attraction effects in the oblique meridian. Vision Res 17:367-374.

Ohzawa I, Sclar G, Freeman RD (1982) Contrast gain control in the cat visual cortex. Nature 298:266-268.

Oyster CW, Takahashi ES (1974) Responses of rabbit superior colliculus neurons to repeated visual stimuli. J Neurophysiol 37:301-312.

Pantle A, Sekuler RW (1968) Size-detecting mechanisms in human vision. Science 162:1146-1148.

Parker DM (1972) Contrast and size variables and the tilt aftereffect. Q J Exp Psychol 24:1-7.

Parker DM (1974) Evidence for the inhibition hypothesis in expanded angle illusion. Nature 250:265-266.

Reynolds RI (1978) 'The microgenetic development of the Ponzo and Zöllner illusions. Percept Psychophys 23:231-236.

Rose D, Lowe I (1982) Dynamics of adaptation to contrast. Perception 11:505-528.

Sekuler R, Littlejohn J (1974) Tilt after-effect following very brief exposures. Vision Res 14:151-152.

Sharpe CR (1974) The colour specificity of spatial adaptation: redblue interactions. Vision Res 14:41-51.

Sillito AM (1977) Inhibitory processes underlying the direction specificity of simple, complex and hypercomplex cells in the cat's visual cortex. J Physiol (Lond) 271:699-720.

Smith RA Jr (1971) Studies of temporal frequency adaptation in visual contrast sensitivity. J Physiol (Lond) 216:531-552.

Sutherland NS (1961) Figural after-effects and apparent size. Q J Exp Psychol 13:222-228.

Thompson SM, Gähwiler BH (1989) Activity-dependent disinhibition. III. Desensitization and $\mathrm{GABA}_{\mathrm{B}}$ receptor-mediated presynaptic inhibition in the hippocampus in vitro. J Neurophysiol 61:524-533.

Tolhurst DJ, Thompson PG (1975) Orientation illusions and aftereffects: inhibition between channels. Vision Res 15:967-972.

Vidyasagar TR, Heide W (1986) The role of GABAergic inhibition in the response properties of neurones in cat visual area 18. Neuroscience 17:49-55.

Wallace GK (1969) The critical distance of interaction in the Zöllner illusion. Percept Psychophys 5:261-264. 
Wallace GK (1975) The effect of contrast on the Zöllner illusion. Vision Res 15:963-966.

Wallace GK, Crampin DJ (1969) The effect of background density on the Zöllner illusion. Vision Res 9:167-177.

Ware C, Mitchell DE (1974) The spatial selectivity of the tilt aftereffect. Vision Res 14:735-737.
Wenderoth P, Johnstone S (1988) The different mechanisms of the direct and indirect tilt illusions. Vision Res 28:301-312.

Wolfe JM (1984) Short test flashes produce large tilt aftereffects. Vision Res 24:1959-1964.

Wolfe JM (1986) Long term visual aftereffects: structural change in the human visual cortex? Soc Neurosci Abstr 12:1184 